\title{
REDUÇÃO DE FALHAS E ENTUPIMENTOS EM UMA PLANTA DE SINTERIZAÇÃO ATRAVÉS DA SUBSTITUIÇÃO DE UM TABLE FEEDER POR UM ALIMENTADOR DE CORREIA*
}

\author{
Rafael Cerqueira Lima ${ }^{1}$ \\ Layda Faustina Anselmo Alas ${ }^{2}$ \\ Jorge Nei Brito ${ }^{3}$
}

\section{Resumo}

Os atuais desafios da Indústria do Aço e Minérios têm feito que empresas busquem otimizar seus processos de tal forma a produzir com a máxima qualidade e com o menor custo possível. Um processo estável possui baixos Índices de Paradas NãoProgramadas, sejam de origem Operacionais ou por Falhas de Equipamentos. $O$ presente artigo descreve a análise realizada em um processo de Sinterização onde em uma de suas etapas havia níveis insatisfatórios de Falhas e de Entupimento de Material. O objetivo principal deste artigo é apresentar os resultados obtidos com a modificação neste processo através da Substituição de um Table Feeder por um Alimentador de Correia e Melhorias realizadas em uma Balança Dosadora.

Palavras-chave: Paradas não programadas; Entupimento; Table Feeder; Alimentador de correia; Balança dosadora.

\section{FAILURES AND BLOCKAGE REDUCTION IN A SINTERING PLANT THROUGH THE REPLACEMENT OF A TABLE FEEDER BY A BELT FEEDER}

\begin{abstract}
The current challenges of the Steel Industry and Minerals have done that companies seek to optimize their processes in such a way to produce with the highest quality and the lowest possible cost. A stable process has low Non Programmed Stops Ratios irrespective of Operating origin or equipment failures. This article describes the analysis performed in a Sintering Process where in one of its steps had unsatisfactory levels of failures and material blocking. The aim of this work is to present the results obtained with a modification of this process by Replacing a Table Feeder by a Belt Feeder and improvements carried out on a Weight Belt Feeder.

Keywords: Non programmed stops; Blocking; Table feeder; Belt feeder; Weight belt feeder.
\end{abstract}

1 Engenheiro Industrial Mecânico, Especialista em Manuseio e Transporte de Materiais a Granel, Diretor Técnico, KPJ Soluções em Engenharia, Juiz de Fora, Minas Gerais, Brasil.

2 Engenheira Industrial Mecânica, Especialista em Transporte Ferroviário, Diretora Comercial, KPJ Soluções em Engenharia, Juiz de Fora, Minas Gerais, Brasil

3 Engenheiro Mecânico, Pós-Doutor em Engenharia Mecânica e Especialista em detecção de falhas em máquinas rotativas através de técnicas preditivas, Professor Pesquisador e Presidente da FENEMI, UFSJ, São João del Rei, Minas Gerais, Brasil. 


\section{INTRODUÇÃO}

Com os atuais desafios da indústria do aço, tanto no Brasil como no mundo, faz-se necessário cada vez mais produzir com a máxima qualidade no menor custo possível. O baixo valor da tonelada do aço no mercado externo e capacidade de produção excedente faz com que a siderurgia se torne cada vez mais competitiva e enfrente esta situação que se arrasta desde o ano de 2008 (1).

O número de Paradas não Programadas, bem como sua duração impacta negativamente no custo de produção de qualquer processo. Outro ponto afetado é o desempenho do processo que está diretamente relacionado à maneira como ele foi projetado, construído e operado.

Este artigo abordará um Processo de Sinterização no qual o número de Paradas não Programadas é relativamente elevado. Tendo-se como uma das principais causas a Baixa Disponibilidade de um Table Feeder e de uma Balança Dosadora. Estes equipamentos apresentaram tanto falhas eletromecânicas, como também, diversos entupimentos de material. A substituição do Table Feeder por um Alimentador de Correia e as Modificações na Balança Dosadora são o resultado final deste trabalho.

\section{MATERIAIS E MÉTODOS}

O Table Feeder é um equipamento de alimentação integrado a uma Balança Dosadora que fornece a quantidade de material solicitada pelo processo. Com o giro da Mesa o material do cone e do silo vai sendo expelido continuamente por um raspador para a Balança Dosadora (2). Este equipamento é usualmente aplicado em Plantas de Sinterização e de Pelotização.

O Table Feeder abordado neste trabalho faz parte de um Processo de Sinterização na qual sua função é retirar o material do interior de um silo onde ocorre a hidratação da cal. A descarga do material ocorre de forma dosada de acordo com a demanda do processo. O presente equipamento possui a Capacidade de Alimentação de 300 a 600t/h, Diâmetro da Mesa de $3.600 \mathrm{~mm}$, Potência Instalada de $55 \mathrm{KW}$ e Velocidade Rotação da Mesa variando de 0,5 a 5rpm. Já a Balança Dosadora possui uma Correia Transportadora com a largura de 54" e Acionamento com Potência de 5,5KW ligado ao Tambor Motriz por conjunto de Corrente de Transmissão.
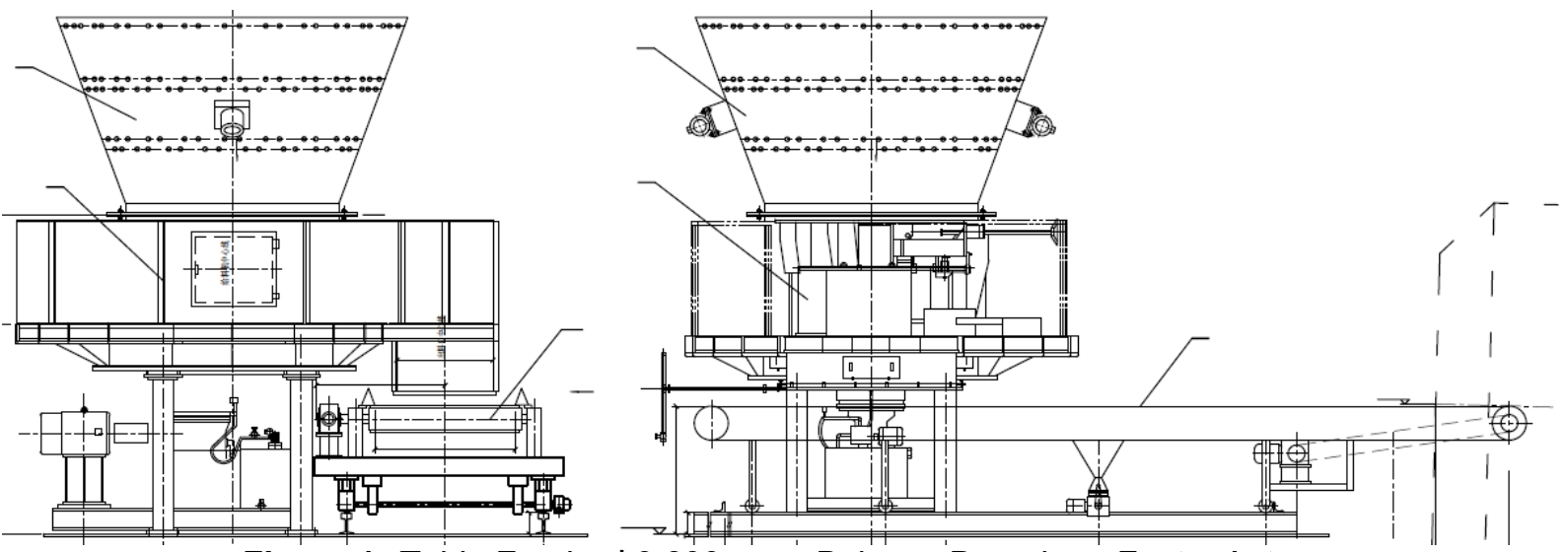

Figura 1. Table Feeder $\Phi 3.600 \mathrm{~mm}$ e Balança Dosadora. Fonte: Autor.

Este Table Feeder e a Balança Dosadora estão locados entre os dois Misturadores da Planta de Sinterização abordada neste trabalho. 


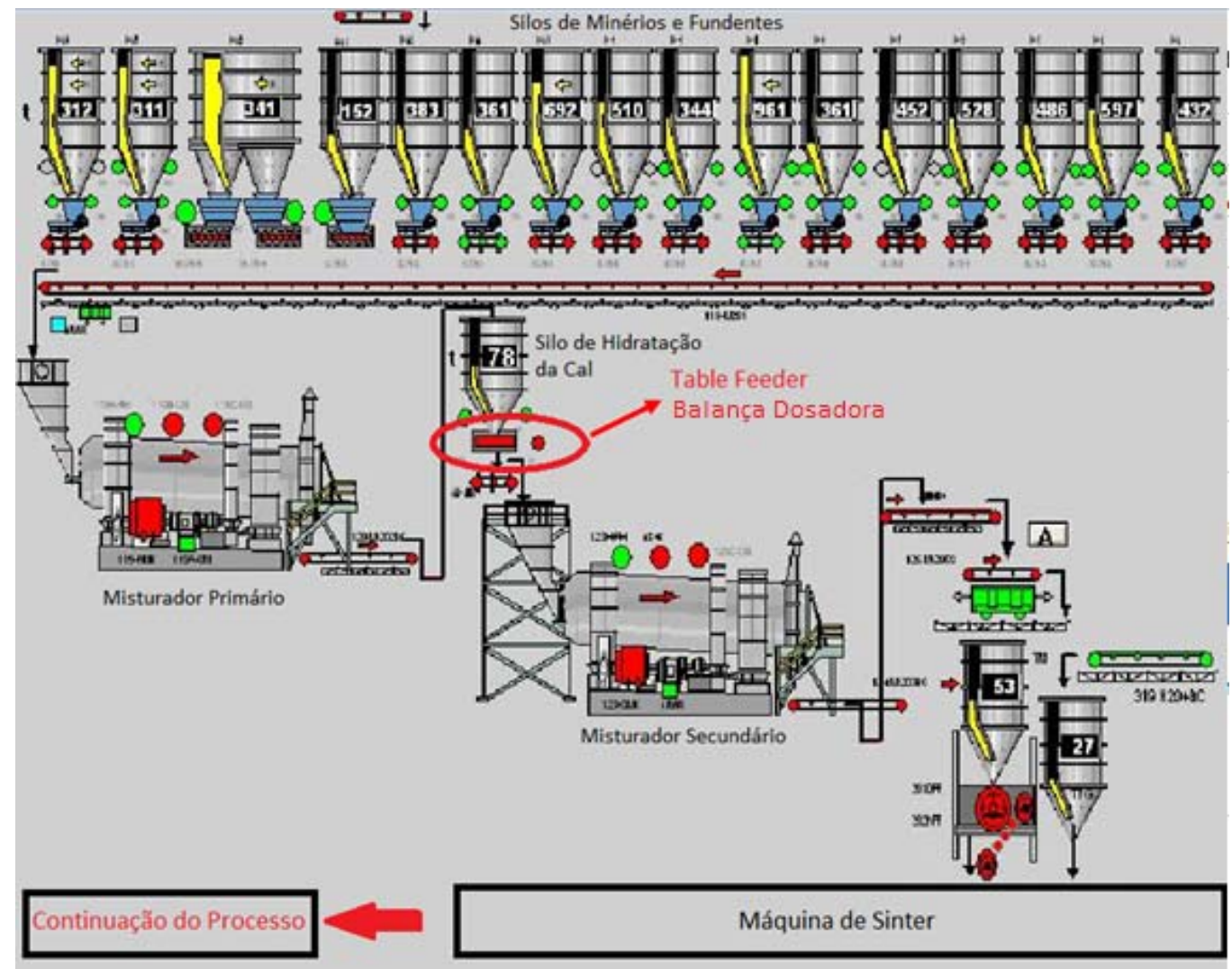

Figura 2. Processo de Sinterização. Fonte: Autor.

Estes dois equipamentos apresentaram grande número de falhas desde o seu startup. Por se tratar de equipamentos montados em linha, todas as paradas desses ocasionam parada total da Planta de Sinterização. Através de gráfico apresentado na Figura 3, pode-se notar o impacto destes equipamentos nas paradas de produção da planta. Abordou-se um período de 34 meses.

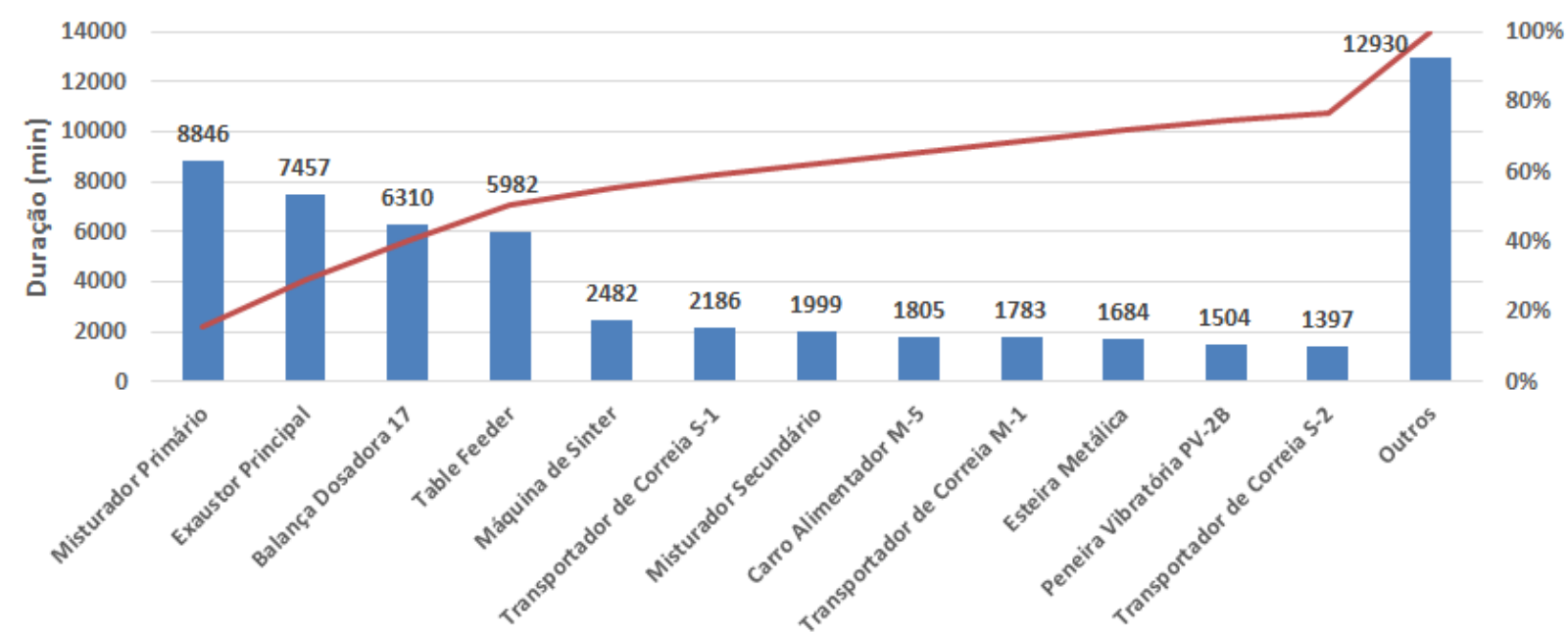

Figura 3. Parada dos Equipamentos da Planta de Sinterização. Fonte: Autor.

Os dois primeiros equipamentos apresentaram grande duração de paradas devido a falha em Motor Elétrico e em Transformador. No período destas falhas esta empresa ainda não possuía sobressalente para estes dois equipamentos, fazendo com que as paradas fossem longas. Já na Balança Dosadora 17 e o Table Feeder ocorreram diversas falhas. 
Toda a análise estatística do trabalho foi realizada através de Gráficos de Pareto.

\section{RESULTADOS E DISCUSSÃO}

Juntos a Balança Dosadora 17 e o Table Feeder correspondem a $21,81 \%$ de todas as paradas ocorridas no período mencionado. Juntos representam 12.992 minutos de parada de planta, ocasionando uma perda de produção de aproximadamente 53.700 toneladas de Sinter.

Também foram estratificadas as falhas para identificação das causas das mesmas no mesmo período de 34 meses.

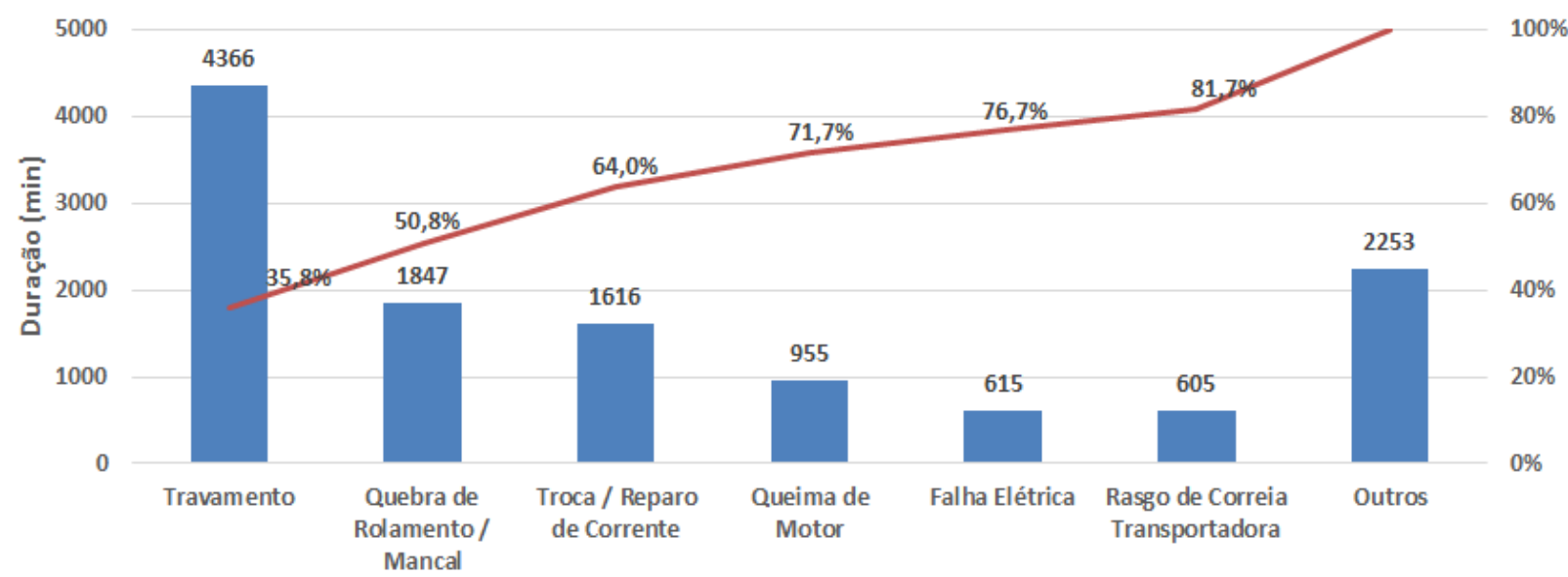

Figura 4. Paradas da Balança Dosadora 17 e do Table Feeder. Fonte: Autor.

No presente trabalho foram abordados os três primeiros maiores problemas que corresponderam a $64 \%$ das paradas destes dois equipamentos no período de 34 meses.

A Falha 'Travamento' foi o que mais impactou nas paradas deste equipamento, dessa forma, motivando uma modificação no mesmo. Inicialmente foram executadas algumas recomendações do fabricante que não surtiram efeito sobre a redução do número de falhas.

Sempre que o Travamento ocorria era necessário que o operador desobstruísse a saída e o interior da mesa com água pressurizada. Esta atividade causava alguns transtornos operacionais tal como, acúmulo de material sobre o piso e equipamentos. Consequentemente, ocorriam quebras e desgaste prematuro de componentes da Balança Dosadora. A através da figura 5 é possível visualizar a saída da mesa com material e após a limpeza com água.
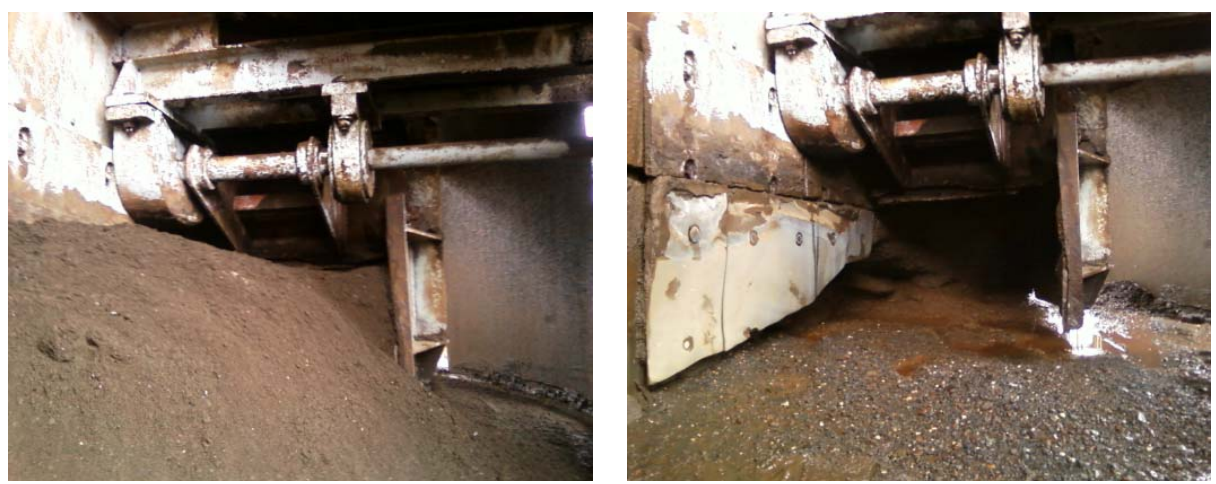

Figura 5. Detalhe da descarga do Table Feeder. Fonte: Autor. 
Após diversas análises e inexistência de resultados positivos com as recomendações do fabricante do equipamento, conclui-se que havia falha de projeto. Este equipamento não possuía potência suficiente para cisalhar o material independentemente da mistura de minério e fundentes utilizada. A modificação da porcentagem de fundentes nesta mistura em específico alteraria tanto a qualidade do sínter, bem como seu custo

Visando mitigar esta situação fez-se um ajuste no Inversor de Frequência, onde houve alteração da Corrente Nominal de 88A para 176A. Dessa forma dobrando a Potência de $55 \mathrm{KW}$ para $110 \mathrm{KW}$ para que o equipamento pudesse romper/cisalhar o material dentro do mesmo. Essa afirmação é feita com base nas seguintes equações de Potência Elétrica e Torque:

$$
\begin{array}{r}
P_{\text {nominal }}=I_{\text {nominal }} \times E \times \sqrt{3} \times \cos \gamma \times \eta \\
T=\frac{P}{n}
\end{array}
$$

Esta modificação não surtiu efeito pelo fato da engrenagem de giro não ter suportado o novo torque e, também, havendo quebra dos parafusos de fixação do cone de alimentação do Table Feeder que é preso ao Silo.
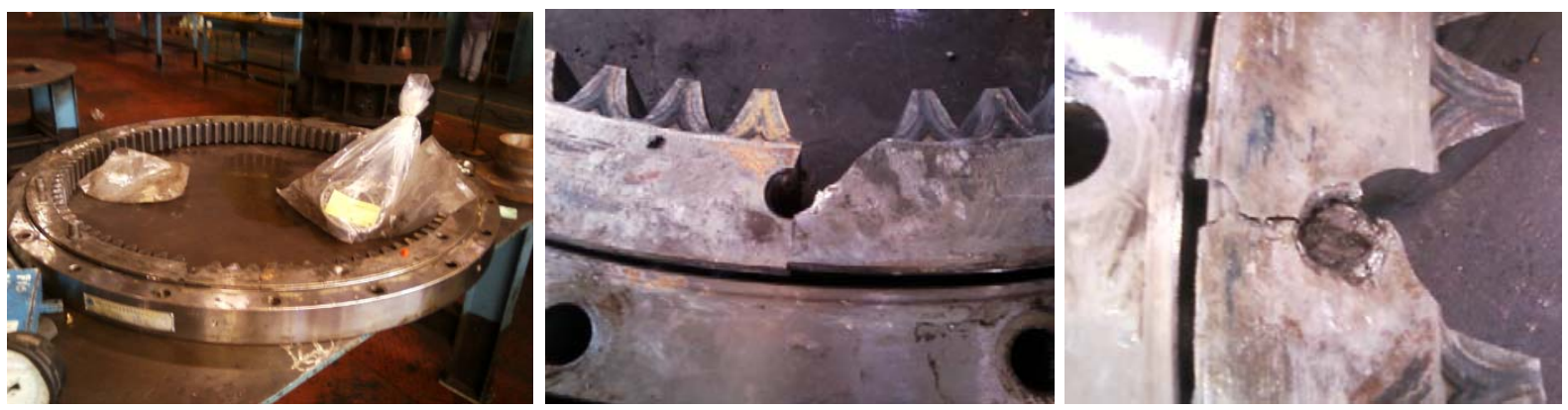

Figura 6. Quebra da Engrenagem de Giro do Table Feeder. Fonte: Autor.

Já a Balança Dosadora apresentava diversas falhas na Corrente de Acionamento do equipamento, bem como nos Mancais utilizados nos Tambores. Equipamentos com transmissão de potência diretamente no eixo do Tambor Motriz da correia normalmente demandam menos recursos de inspeção e manutenção. Já rolamentos esféricos de mancais do Tipo $\mathrm{Y}$ projetados para este equipamento suportam uma carga 3 vezes menor que rolamentos autocompenssadores de rolos em caixas de mancais do tipo SBP. Outro ponto negativo dos mancais do Tipo $Y$ é a vedação deficiente para este tipo de aplicação.
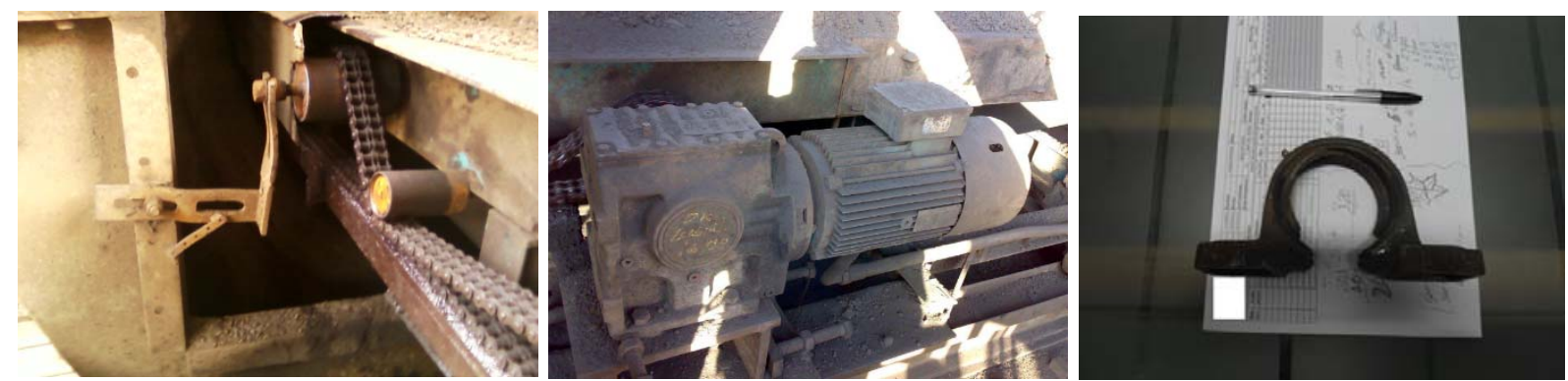

Figura 7. (a) Detalhe do tensionador da corrente; (b) Acionamento da correia transportadora da balança; (c) Mancal do Tambor de retorno avariado. Fonte: Autor. 
Mediante as análises do Table Feeder e da Balança Dosadora, chegou-se à conclusão que o Table Feeder deveria ser substituído por um novo ou por um Alimentador de Correia. Já a Balança Dosadora receberia melhorias em seu acionamento e nos Tambores. Além da substituição dos Mancais e Rolamentos por outros mais resistentes a cargas e a sujidade do ambiente.

Pelo fato da substituição do Table Feeder por um Alimentador de Correia ter sido uma alternativa com menor custo (cerca de $75 \%$ ), essa proposta foi implantada com as seguintes especificações apresentadas na Tabela 1 e Figura 8.

Tabela 1. Dados do Transportador. Fonte: Autor.

\begin{tabular}{lc|lc}
\hline Item & Descrição & Item & Descrição \\
\hline Capacidade Máxima & $650(700) \mathrm{t} / \mathrm{h}$ & Tipo de Roletes & Planos \\
\hline Velocidade Máxima & $0,724 \mathrm{~m} / \mathrm{s}$ & Comprimento & $3.000 \mathrm{~mm}$ \\
\hline Potência Requerida & $23,248 \mathrm{CV}$ & Largura da Correia & 60 pol. \\
\hline Potência Instalada & $30 \mathrm{CV}$ & & \\
\hline
\end{tabular}

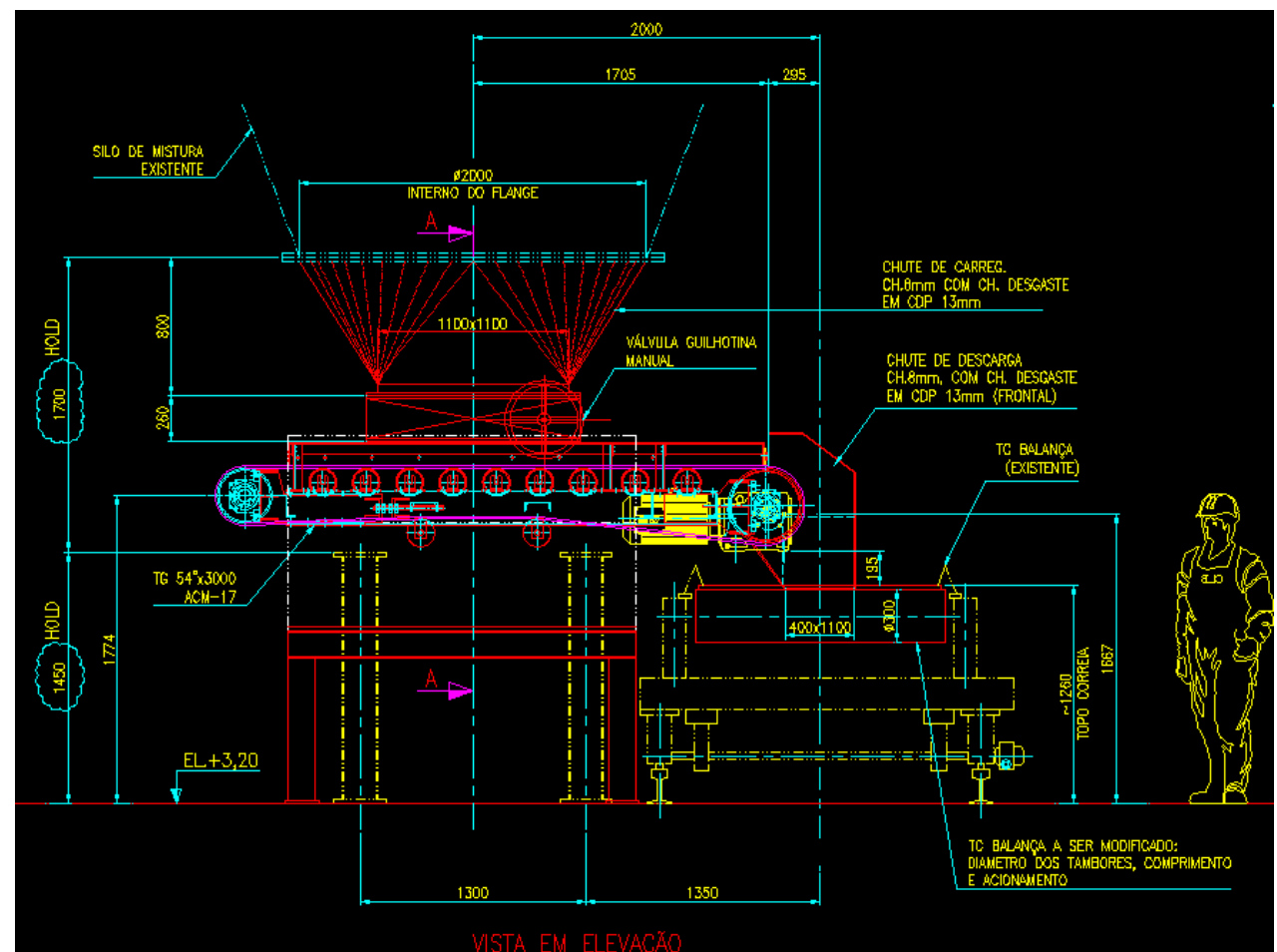

Figura 8. Arranjo Geral do novo Alimentador de Correia. Fonte: Autor.

Estas especificações foram obtidas através das Fórmulas 3 e 4, onde é calculada a Tensão Efetiva que leva em consideração todas as resistências presentes no Transportador de Correia (3).

$$
\begin{array}{r}
T_{e}=\mathrm{L} \times K_{t}\left(K_{x}+K_{y} \times W_{b}+0,015 \times W_{b}\right)+W_{m}\left(L \times K_{y}+H\right)+T_{p}+T_{a m}+T_{a c} \\
N_{e}=\frac{T_{e} \times V}{75}
\end{array}
$$

Para o novo equipamento o item mais crítico projetado foi o Cone de Ligação do Silo com o Alimentador de Correia. Este cone deveria estar livre de pontos de ancoragem para o material, além de possuir uma geometria que possibilitasse o seu bom escoamento. 
Também foi levado em consideração o volume de material que exerceria carga sobre o Alimentador de Correia para que sua potência fosse calculada. Utilizou-se a premissa de que materiais a granel não apresentam comportamento similar aos líquidos. Nestes materiais a relação das cargas na saída do silo não aumentam em função do enchimento do silo (4). Neste projeto foi adotado uma transição suave com um ângulo que permitisse o máximo escoamento de material conforme é apresentado na figura 9.
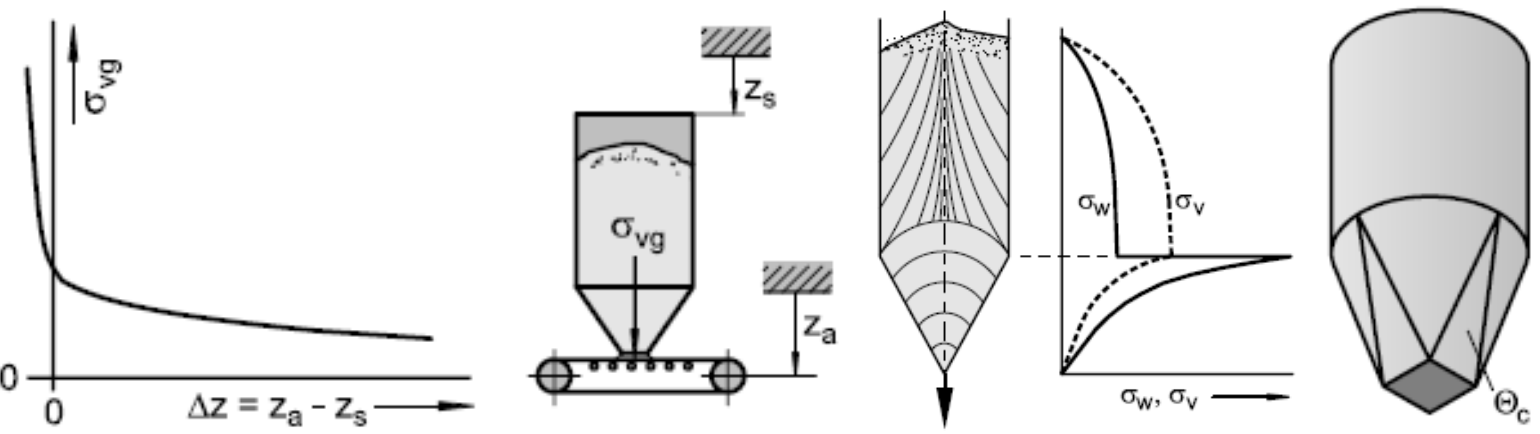

Figura 9. Projeto do Cone: (a) Relação das Tensões Verticais com a Altura ; (b) Distribuição de Tensão no Interior do Silo; (c) Demonstração da descarga do Silo no Alimentador de Correia (3). Fonte: Schulze

A Balança Dosadora também passou por melhorias. O acionamento foi ligado diretamente no eixo do Tambor Motriz que ficou no retorno da correia. Com isso, eliminou-se a necessidade do uso de corrente de transmissão. Os mancais e rolamentos dos Tambores também foram substituídos por outros mais resistentes à carga e de melhor vedação. Substituiu-se os mancais do tipo $Y$ para SBP e os rolamentos esféricos para autocompenssadores de rolos.

A atividade de substituição do Table Feeder pelo Alimentador de Correia e as Melhorias na Balança Dosadora foram executadas em um período de 48 horas de atividade.

Estes novos equipamentos tiveram seu desempenho mensurado durante o período de 12 meses e apresentaram grande redução de falhas, inclusive durante alguns meses com inexistência dessas.
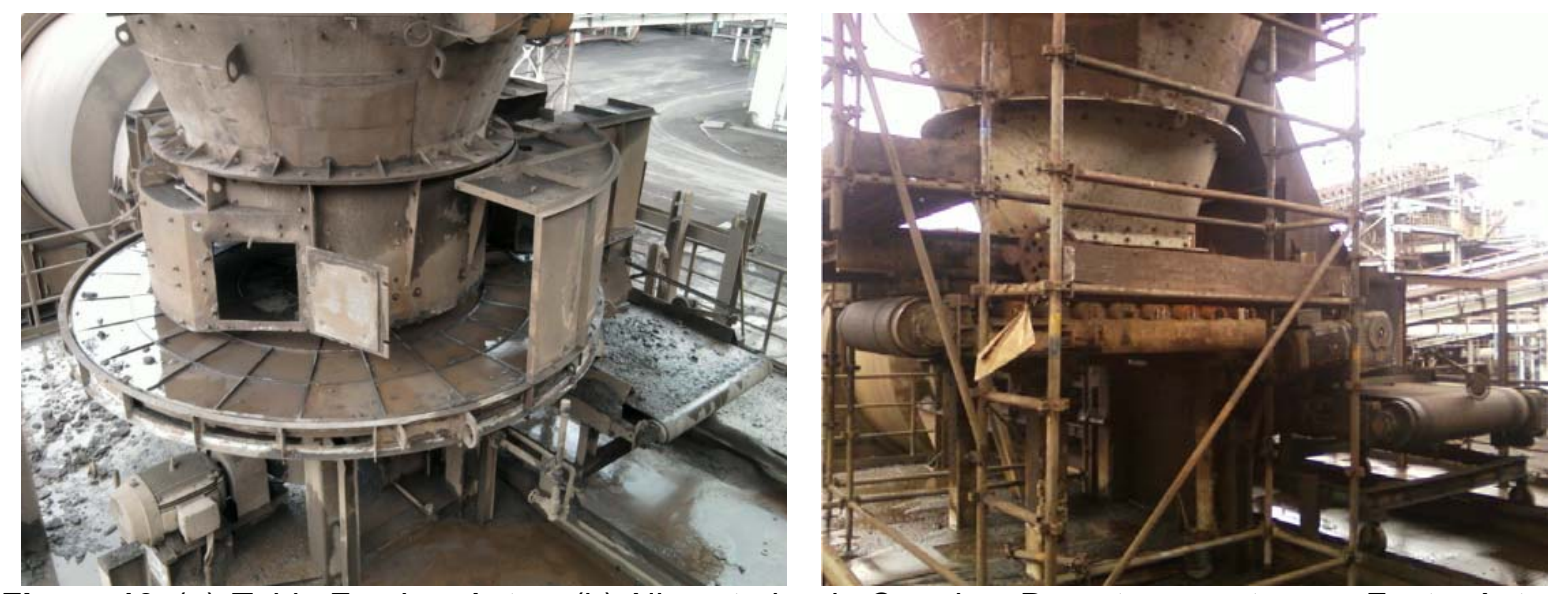

Figura 10. (a) Table Feeder - Antes; (b) Alimentador de Correia - Durante a montagem. Fonte: Autor. 


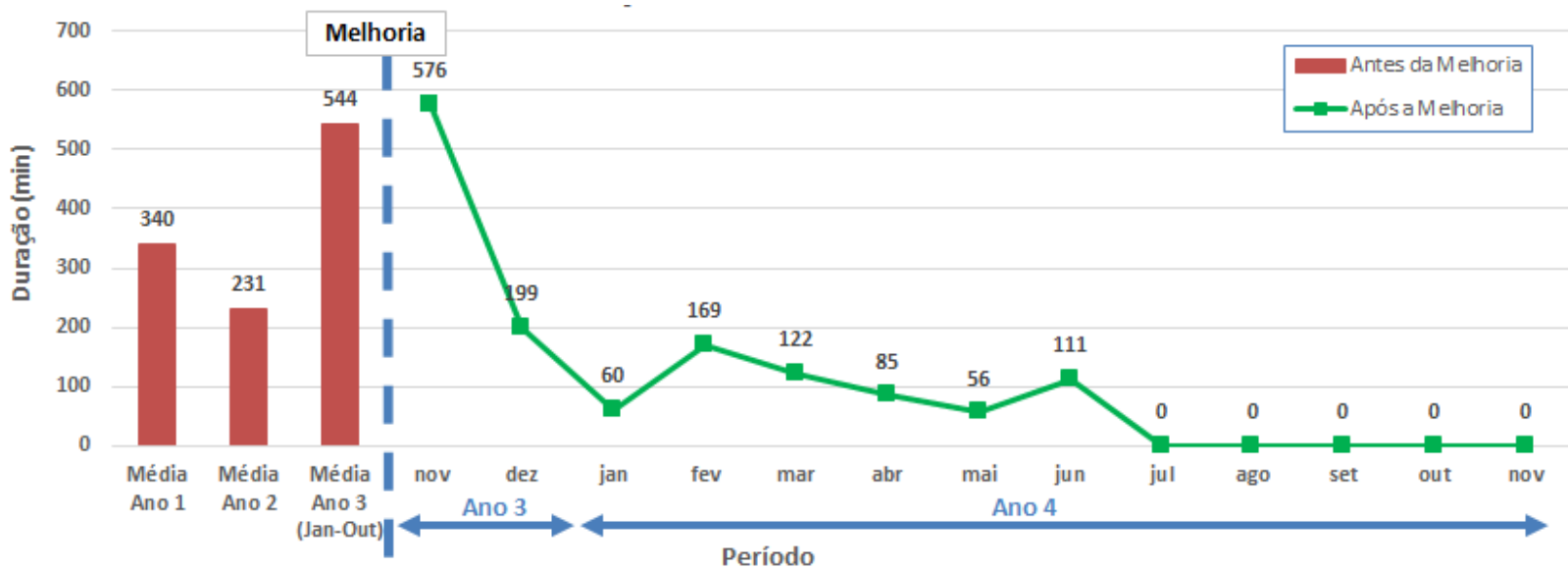

Figura 11. Histórico de Falhas e Resultados obtidos com a Modificação. Fonte: Autor.

Através do gráfico apresentado na Figura 11 nota-se a redução drástica de falhas no Alimentador de Correia (substituto do Table Feeder) e da Balança Dosadora 17. Nos meses de Dezembro do Ano 3 e Janeiro do Ano 4 foram necessárias a realização de modificações no projeto das Guias Laterais do Alimentador de Correia e Retirada da Comporta Ajustável da saída do Cone.

A presença de 'Matacos' (ROM - Run of Mine) forçou a retirada da comporta mencionada. A presença desses blocos com granulometria superior a 5 polegadas estrangulava a saída de material causando rasgos na correia e deformação da comporta e em outras estruturas.
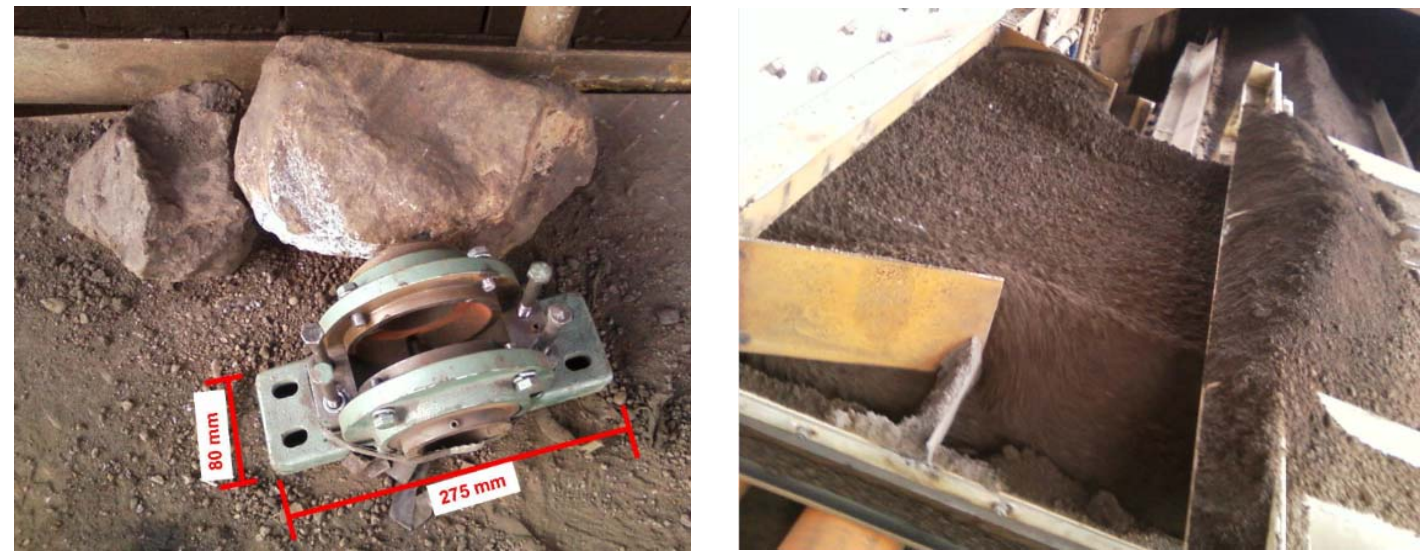

Figura 12. (a) Exemplo de Mataco presente na mistura; (b) Saída do Cone do Alimentador de Correia sem a Comporta Ajustável. Fonte: Autor.

A retirada da comporta possibilitou que esses materiais fluíssem naturalmente sem causar danos ao Alimentador de Correia e a Balança Dosadora 17. Neste processo em questão os 'Matacos' estavam inerentes a mistura e até a execução deste trabalho não havia estratégia para eliminá-los.

A presença de partículas com granulometria superior a 1 polegada também forçou modificações na guia lateral. $O$ fato de se prenderem nas guias ocasionou desgaste acentuado da correia com consequente rasgo longitudinal. Nesta situação a guia que era reta foi alterada para o formato de cunha.

Com a execução deste trabalho é nítida a redução de falha nestes equipamentos. Há também o ganho financeiro obtido com a execução deste projeto que foi de $\mathrm{R} \$ 693.526,29$. O cálculo deste valor leva em consideração o Plano de Produção 
Orçado para a Planta, Rendimento do Sinter, Custo Variável do Sinter, Relação de Substituição de Sinter por Minério Granulado 'Y' e Preço do Minério Granulado ' $Y$ '. O ganho apresentado foi calculado apenas sobre os ganhos operacionais, há também redução de custo com a manutenção destes equipamentos que não foram mensuradas.

Este trabalho possuiu o custo aproximado de $\mathrm{R} \$ 295.000,00$ (Projeto e Fabricação) fazendo com que seu Tempo de Payback fosse curto, inferior a 6 meses.

\section{CONCLUSÃO}

Com base nas análises realizadas e resultados obtidos no presente trabalho é possível afirmar que mesmo para um equipamento robusto e bem apropriado para a função que desempenhará, o seu dimensionamento e projeto possuem papel fundamental na sua operacionalidade. O Table Feeder é um equipamento vastamente aplicado com sucesso em plantas de Sinterização e Pelotização, mas neste caso em específico foi falho devido ao seu mal dimensionamento.

Comparado ao Table Feeder,o Alimentador de Correia é mais frágil e requer mais cuidados com o material manuseado. Matacos ou grãos maiores de minério podem danificar a correia transportadora com maior facilidade do que causar danos ao Table Feeder. Caso haja contenção de matacos a vida útil da correia transportadora será ainda maior.

Ambos os equipamentos possuem excelente eficiência quando bem operados e quando possuem bons padrões de manutenção que são executados de maneira adequada.

Para a solução do problema deste trabalho foi selecionado o Alimentador de Correia devido ao seu custo bastante inferior em relação a um novo Table Feeder. Por se tratar de um equipamento mais simples a sua manutenção também é mais simples, podendo-se utilizar os mesmos padrões de inspeção em Transportadores de Correia.

A efetividade deste trabalho se resume no projeto de um equipamento bem dimensionado, que desempenha bem a sua função e que permite que a equipe de manutenção possa lidar com o mesmo de forma simples e objetiva. Todo projeto do Alimentador de Correia e as modificações na Balança Dosadora levaram em consideração algumas premissas de componentes robustos, de maior vida útil e normalmente já aplicados em outros equipamentos.

Nos melhores equipamentos a fase de projeto contempla estudos para que o mesmo opere com a maior eficiência e que a manutenção seja simples. Bons acessos às intervenções e componentes comuns que sejam facilmente encontrados no almoxarifado da empresa melhoram a aceitação do equipamento. Somando-se a limpeza adequada do equipamento com a execução dos planos de inspeção e manutenção, será possível garantir um excelente desempenho para o equipamento bem projetado, assim garantindo baixos índices de falhas.

\section{REFERÊNCIAS}

1 CNI - Confederação Nacional da Indústria. A Indústria do Aço no Brasil. 2012 [acesso em 10 dez. 2015];1:45-46. Disponível em: http://www.acobrasil.org.br/site/portugues/ sustentabilidade/downloads/livro_cni.pdf .

2 Landcast Products. How Table Feeders Work \& Table Feeder Construction. [acesso em 14 jan. 2016]. Disponível em: http://www.lancasterprd.com/table-feeders-work-tablefeeder-construction/ . 
$46^{\circ}$ Redução

$17^{\circ}$ Minério de Ferro

$4^{\circ}$ Aglomeração

3 CEMA - Conveyor Equipment Manufacturers Association. Belt Conveyors for Bulk Materials. 2004; 1:95-104.

4 Schulze D. Powders and Bulk Solids - Behaviors, Characterization, Storage and Flow. Springer. 2008; 1:4-5, 253, 274, 320-322. 